\title{
Korelasi Self Efficacy Dengan Hasil Pembelajaran Biologi di SMA 1 Rambatan Kabupaten Tanah Datar Sumatera Barat
}

\section{Self EfficacyCorrelation With Biological Learning Results In High School 1 Rambata, Districts Tanah Datar West Sumatra}

\section{Diyyan Marneli*, Hanif Dirma, Rina Delfita}

Department of Biology Education, Faculty of Education and Teacher Training, Institut Agama Islam Negeri Batusangkar. *Correspondent email: diyyanmarneli@iainbatusangkar.ac.id

Received: 30 September 2020 | Accepted: 30 Desember 2020 | Published: 30 Desember 2020

\begin{abstract}
Abstrak. Penelitian ini didasari karena banyak siswa yang memiliki self efficacy yang rendah dalam pembelajaran biologi dikarenakan siswa masih kurang peduli terhadap tujuan dalam mengikuti pembelajaran biologi. Penelitian ini bertujuan untuk mengetahui korelasi antara self efficacy dengan hasil pembelajaran biologi pada kelas XI SMA 1 Rambatan. Metode yang digunakan ialah metode deskriptif kuantitatif dengan pendekatan korelasional. Subjek pada penelitian ini adalah siswa kelas XI. Pengumpulan data dilakukan dengan mengunakan instrument angket dan nilai hasil belajar siswa. Teknik analisis data yang digunakan pada penelitian ini adalah uji Korelasi Product Moment dan uji signikafikansi dengan uji $t$. Hasil penelitian menunjukkan terdapat hubungan positif yang signifikan antara self efficay dengan hasil pembelajaran biologi, pada kriteria sedang. Namun demikian hasil penelitian ini menunjukkan self efficacy siswa bukanlah satu-satunya faktor untuk meningkatkan hasil pembelajaran biologi siswa, tetapi masih banyak lagi faktor yang mampu mempengaruhinya.

Kata kunci: Self Efficacy Siswa, Pembelajaran Biologi, Hasil Belajar

Abstract. This research is based on the fact that many students have low self-efficacy in learning biology because students still do not care about the goals in learning biology. This study aims to determine the correlation between self-efficacy and the results of learning biology in class XI SMA 1 Rambat. The method used is a quantitative descriptive method with a correlational approach. The subjects in this study were students of class XI. The data was collected using a questionnaire instrument and the student learning outcomes. The data analysis technique used in this research is the Product Moment Correlation test and the significance test with the t test. The results showed that there was a significant positive relationship between self-efficacy and biology learning outcomes, on moderate criteria. However, the results of this study indicate that student self-efficacy is not the only factor to improve student biology learning outcomes, but there are many more factors that can influence it.
\end{abstract}

Keywords: Student Self Efficacy, Biology Learning, Learning Outcomes

\section{PENDAHULUAN}

Biologi merupakan salah satu cabang ilmu pengetahuan alam yang dipelajari pada tingkat pendidikan menengah atas, biologi merupakan ilmu yang berkaitan erat dengan kehidupan sehari-hari, selain menghafal materi, siswa juga dituntut untuk mampu mengaitkan teori yang didapat dengan peristiwa sehari-hari (Herdani et al., 2015). Ruang lingkup biologi yang begitu luas, baik secara deskriptif dan teoristik, telah membuat siswa merasa kesulitan dalam mempelajari biologi secara menyeluruh sehingga tidak terjadi peningkatan hasil belajar siswa. Menurut Hanifah dan Agustini, (2012) menyatakan bahwa self efficacy diperlukan agar pembelajaran dapat berjalan dengan baik. Maka dalam pembelajaran biologi perlu juga untuk diamati self efficacy siswa, agar mampu melihat keyakinan siswa dalam pembelajaran biologi. 
Peningkatan hasil belajar pada siswa memerlukan perhatian untuk meraih prestasi di sekolah. Oleh karena itu, peningkatan hasil belajar dapat dipengaruhi oleh perspektif kognitif yang terdapat empat proses. Empat proses kognitif itu terdiri dari (1) atribusi, (2) motivasi untuk menguasai keahlian, (3) self efficacy, (4) penentuan tujuan, perencanaan, dan monitoring (Santrock, 2013). Melalui proses self efficacy mampu dikembangkan tingkah laku, nilai-nilai dan emosi. Hal ini menjadikan self efficacy mampu mempengaruhi pilihan aktivitas, tujuan, usaha, pembelajaran dan prestasi seorang siswa (Ormrod, 2010).

Pembelajaran bukanlah satu-satunya faktor yang menentukan prestasi belajar, karena prestasi merupakan hasil belajar (Arikunto, 2010). Adapun faktor yang mempengaruhi hasil belajar siswa, yaitu: faktor internal dan eksternal. Internal yaitu dari dalam diri individu yang meliputi faktor fisiologis (fisik) dan faktor psikologis (jiwa). Sedangkan faktor eksternal yaitu dari luar diri individu yang meliputi faktor lingkungan sosial, faktor lingkungan non-sosial, dan faktor pendekatan belajar (Suryabrata, 2011). Salah satu faktor psikologis yang mampu mempengaruhi hasil belajar adalah self efficacy. Pendapat yang sama juga dikemukan oleh Schunk dan Meece, (2006) menyatakan bahwa self efficacy mampu memberikan pengaruh yang kuat terhadap hasil belajar siswa, karena self efficacy dapat mempengaruhi kemampuan siswa dalam mengerjakan tugas-tugas, keseriusan atau ketekunan, dan prestasi siswa dalam pembelajaran. Oleh karena itu, seseorang siswa harus mampu menghadapi pembelajaran sebagai tuntutan zaman yang semakin pesat. self efficacy sangat diperlukan siswa agar mampu mencapai tujuan di dalam hidupnya.

Self efficacy merupakan kemampuan mempengaruhi diri dengan motivasi dan tindakan agar mencapai hasil ataupun tujuan dan juga berapa lama tahan terhadap kesulitan itu (Bandura, 2010). Pada self efficacy terdapat 3 dimensi sebagai indikator untuk mengetahui tingkatan dan dari mana sumber yang menyebabkan keyakinan meningkat. Dimensi self efficacy menurut Pajares, (2003), adalah level, strength, dan generality, karena itu self efficacy seseorang akan berbeda satu dengan yang lainnya, karena berbedaan dimensi self efficacy yang dimiliki seseorang berbeda (Hairida, 2017). Sebagaimana yang dikemukakan Santrock, (2013) bahwa self efficacy adalah keyakinan seseorang untuk dapat menguasai situasi dan menghasilkan hasil yang positif. Sedangkan Schunk dan Meece, (2006) menyatakan bahwa seseorang yakin terhadap dirinya sendiri untuk menghadapi perbedaan dan akhirnya mendapat hasil yang baik. Oleh karena itu, self efficacy sering disebut suatu keyakinan diri (efikasi diri).

Menurut Alfurofika et al., (2013), bahwa siswa yang merasa berkemampuan tinggi tetapi tidak diikuti oleh kerja keras untuk mencapainya masih sebatas tahap motivasi belum pada tahap real self eficacy. Maka siswa diharapkan memiliki keyakinan akan kemampuannya dan juga harus mampu melakukan untuk tercapaiannya tujuan di dalam pembelajaran tersebut sesuai dengan yang diharapkan. Setiap siswa memiliki karakteristik yang berbeda, ini terlihat dari usia siswa SMP dan SMA. Rustaman, (2012) menyatakan bahwa siswa SMP memiliki humor yang tinggi dan memiliki rasa kebersamaan yang tinggi, sedangkan siswa SMA memiliki karakteristik lebih tenang juga memiliki pertumbuhan dan perkembangan yang baik, emosi, dan tanggung jawab. Oleh karena itu, apabila siswa tidak memiliki keyakinan dalam dirinya untuk mengikuti pembelajaran dan juga mengerjakan tugas-tugas sekolah, siswa tersebut akan mengalami kegagalan seperti menghindari tugas-tugas itu, kemudian akan mengalami kesulitan belajar.

Kondisi ini tidak jauh berbeda dengan permasalahan pada proses pembelajaran di kelas XI MIPA SMA Negeri 1 Rambatan. Berdasarkan observasi dan wawancara pada tanggal 16 
Juli 2019 diketahui siswa-siwa kelas XI MIPA di SMA Negeri 1 Rambatan, terlihat ada siswa yang memiliki self efficacy tinggi, juga ada yang memiliki self efficacy rendah. Pada siswa yang memiliki self efficacy yang tinggi memiliki kemampuan belajar yang baik, tekun, rajin, mandiri, lebih aktif, dan banyak mengerjakan tugas-tugas yang bermanfaat. Sedangkan siswa yang memiliki self efficacy rendah menunjukkan kemampuan belajar yang kurang baik, tidak focus, banyak bermain, bercanda dengan teman, sering keluar masuk, dan sering tidak membuat tugas. Siswa yang memiliki self efficacy sedang, cenderung ikut-ikutan teman.

Melihat hasil wawancara tersebut bahwa perlu dilakukan penilaian self efficacy terhadap siswa. Penilaian seseorang terhadap self efficacy memainkan peran yang cukup baik dalam melakukan pendekatan terhadap tujuan, tugas, dan tantangan. Keyakinan ini akan mengarahkan siswa untuk mengetahui batas-batas kemampuan yang dirasakan, agar menuntut siswa berperilaku secara mantap dan efektif dalam mencapai hasil yang baik.

Berdasarkan uraian di atas penelitian ini bertujuan untuk mengetahui sejauhmana peran self efficacy siswa dapat mempengaruhi hasil pembelajaran biologi pada siwa kelas XI MIPA di SMA Negeri 1 Rambatan, Kabupaten Tanah Datar, Sumatra Barat.

\section{METODE PENELITIAN}

Metode penelitian yang digunakan adalah metode kuantitatif. Metode kuantitatif adalah metode yang bertolak dari anggapan bahwa sesuatu gejala-gejala dapat diukur dan diubah ke bentuk angka (Lufri, 2010), rancangan penelitian yang digunakan adalah korelasional. Menurut Rustaman, (2012) penelitian korelasional bertujuan untuk menguji ada atau tidak adanya hubungan yang seberapa besar kekuatan hubungan antar variebel tersebut. Maka hal itu, Teknik analisis data yang digunakan ialah korelasi product moment. Korelasi product moment ini merupakan suatu teknik untuk mencari tingkat hubungan antara dua variabel, adapun nama lain dari korelasi Product Moment disebut dengan korelasi pearson. .

Dalam penelitian ini peneliti mengambil lokasi di SMA 1 Rambatan pada Tahun Ajaran 2019/2020. Teknik sampling yang digunakan ialah probabilitas sampling, populasi pada penelitian ini adalah siswa kelas XI di SMAN 1 Rambatan, yang terdiri dari tiga kelas dengan jumlah siswa 92 Siswa. Jenis pengambilan sampling dengan cara simple random sampling yang merupakan teknik pengambilan sampel secara acak karena setiap anggota unit mendapat kesempatan sama untuk dipilih (Lufri, 2010). Pengambilan sampel yang dilakukan dalam penelitian ini yaitu Simple Random Sampling, dalam teknik pengambilan sampel hal yang dilakukan adalah (1) Mengumpulkan nilai mentah ulangan harian biologi kelas XI MIPA SMA Negeri 1 Rambatan tahun ajaran. 2019/2020, (2) Melakukan uji normalitas, (3) Uji homogenitas dan (4) Melakukan analisis variansi satu arah untuk melihat kesamaan populasi.

\section{Prosedur Penelitian}

Prosedur penelitian dimulai dengan tahap pendahuluan, tahap pelaksanaan dan tahap analisis. Teknik pengambilan data yang digunakan adalah: (1) Angket, Dalam penelitian ini, peneliti memberikan angket self efficacy siswa kepada objek penelitian yaitu siswa kelas XI SMA Negeri Rambatan. Angket memuat pernyataan yang disertai dengan pilihan-pilihan jawabannya. Angket yang disusun berjumlah 65 butir item pernyataan dan diuji coba pada kelas XI MIPA 1 yang berjumlah 36 siswa. Pada angket memiliki 2 macam pernyataan, yaitu 
pernyataan positif dan negatif. Skala self efficacy yang digunakan disusun dalam bentuk skala likert, yang terdiri dari aspek self efficacy yang dapat diukur, dengan pilihan dan bobot skor seperti tabel berikut:

Tabel 1 . Skala likert angket self efficacy

\begin{tabular}{clcc}
\hline \multirow{2}{*}{ No. } & \multirow{2}{*}{ Jawaban siswa } & \multicolumn{2}{c}{ Skor untuk setiap pertanyaan } \\
\cline { 3 - 4 } & & Positif & Negatif \\
\hline 1 & Sangat setuju (SS) & 5 & 1 \\
2 & Setuju (S) & 4 & 2 \\
3 & Tidak menjawab (TM) & 3 & 4 \\
4 & Tidak setuju (TS) & 2 & 5 \\
5 & Sangat tidak setuju (STS) & 1 &
\end{tabular}

Modifikasi dari: (Subana dan Sudrajat, 2015)

\section{Teknik Pengumpulan Data}

Teknik pengempulan data berupa (1) menyusun angket, (2) analisis butir angket, (3) validitas angket, dan (4) wawancara dan sudah di validasi secara keseluruhan. Teknik Analisis Data yang digunakans adalah Sebelum mengadakan analisis uji t dilakukan pemeriksaan data melalui uji persyaratan analisis, yaitu :

(1). Uji normalitas, uji ini bertujuan untuk mengetahui apakah sampel tersebut berdistribusi normal atau tidak. Uji ini dikenal dengan uji liliefors

(2). Regresi linear sederhana. Persamaan regresi linear sederhana yaitu sebagai berikut:

$$
\begin{aligned}
& Y=a+b X \\
& a=\frac{\left(\sum Y\right)\left(\sum X^{2}\right)-\left(\sum X\right)\left(\sum X Y\right)}{N\left(\sum X^{2}\right)-\left(\sum X\right)^{2}} \\
& b=\frac{N\left(\sum X Y\right)-\left(\sum X\right)\left(\sum Y\right)}{N\left(\sum X^{2}\right)-\left(\sum X\right)^{2}} \\
& r_{x y}=\frac{N\left(\sum X Y\right)-\left(\sum X\right)\left(\sum Y\right)}{\sqrt{\left\{N\left(\sum X^{2}\right)-\left(\sum X\right)^{2}\right\}\left\{N\left(\sum Y^{2}\right)-\left(\sum Y\right)^{2}\right\}}}
\end{aligned}
$$

(3). Mencari interval, dalam penelitian ini variabel dependennya adalah tingkat hasil belajar Biologi dan independennya adalah self efficacy siswa. Metode analisis regresi linier sederhana ini dilakukan dengan menggunakan rumus untuk mengelola data statistik. Untuk data self efficacy dan hasil belajar yang didapatkan interval data dengan langkahlangkah:

a. Banyak kelas interval (aturan Stuges).

b. Hitung jumlah kelas $[K=1+3,3 \log n]$

c. Hitung jarak atau rentang [R= data terbesar-data terkecil].

d. Hitung panjang kelas interval $[\mathrm{P}=$ Rentang/jumlah kelas $]$

(4). Uji hipotesis, uji hipotesis digunakan untuk menguji hipotesis penelitian diajukan pada penelitian ini. Untuk menguji hipotesis tersebut digunakan teknik analisis data product moment dengan rumus:

$$
r_{x y}=\frac{n \cdot\left(\sum X Y\right)-\left(\sum X\right)\left(\sum Y\right)}{\sqrt{\left\{n\left(\sum X^{2}\right)-\left(\sum X\right)^{2}\right\}\left\{n\left(\sum Y^{2}\right)-\left(\sum Y\right)^{2}\right\}}}
$$


(5). Uji signifikan, analisis ini dimaksudkan untuk menguji data tentang hubungan antara variabel X dengan variabel Y, maka hasil korelasi Product Moment tersebut diuji dengan uji signifikansi menggunakan rumus:

$$
t_{\text {hitung }}=\frac{r_{\sqrt{n-2}}}{\sqrt{1-r^{2}}}
$$

\section{HASIL DAN PEMBAHASAN}

Berdasarkan dari hasil analisis deskriptif data bahwa setiap indikator self efficacy siswa memiliki persentase yang cukup tinggi. Nilai persentase setiap indikator eelf efficacy siswa bisa dilihat pada tabel berikut:

Tabel 2. Persentase Indikator self efficacy Siswa

\begin{tabular}{clllll}
\hline No. & Sub Indikator & Jumlah Item & Jumlah Skor & Skor Maksimal & $\begin{array}{l}\text { Persentase } \\
\text { Indikator }\end{array}$ \\
\hline 1 & Level/Magnitude & 10 & 2003 & 2650 & $75,58 \%$ \\
2 & Strenght & 10 & 1945 & 2650 & $73,39 \%$ \\
3 & Generality & 10 & 1990 & 2650 & $75,09 \%$ \\
\hline
\end{tabular}

Pada tabel di atas, hasil analisis deskriptif untuk setiap indikator self efficacy memiliki persentase yang cukup tinggi meliputi level/magnitude termasuk kedalam kategori tinggi dengan persentase $75,58 \%$, strenght termasuk kedalam kategori tinggi dengan persentse 73,39\%, Generality termasuk kedalam kategori tinggi dengan persentase 75,09\%.

Berdasarkan hasil penelitian diketahui bahwa terdapat hubungan positif namun tidak signifikan antara self efficacy siswa dengan hasil pembelajaran biologi kelas XI MIPA di SMAN 1 Rambatan. Hasil perhitungan koefisien korelasi product moment yang dilanjutkan dengan koefisien determinasi yang diperoleh $r_{\mathrm{xy}}=0,0009069578$ dan $\mathrm{KD}=0,00000161 \%$ dari pernyataan tersebut dapat dikatakan bahwa variabel X (self efficacy) dengan variabel $\mathrm{Y}$ (hasil pembelajaran biologi) memiliki hubungan yang sangat lemah atau sangat rendah dan variabel X memberikan pengaruh yang terhadap variabel $\mathrm{Y}$ hanya sebesar $0,00000161 \%$. Hasil penelitian membuktikan bahwa self efficacy siswa merupakan salah satu faktor yang mempengaruhi hasil pembelajaran biologi, namun sangat rendah hingga mampu diabaikan begitu saja.

Hal ini terlihat pada hubungan self efficacy siswa dengan hasil pembelajaran biologi karena self efficacy yang muncul dari dalam atau luar diri siswa sangat rendah, dengan demikian self efficacy yang bertujuan untuk mendorong siswa untuk berbuat, menentukan arah perbuatannya dan menyeleksi perbuatan tersebut untuk mendapatkan hasil belajar. Hal ini sesuai dengan (Sudjana, 2011) menegaskan bahwa hasil belajar siswa adalah komponenkomponen yang dimiliki oleh siswa setelah ia menerima pengalaman belajarnya. Hal ini menjadikan self efficacy sebagai salah satu faktor penyebab yang harus diperhatikan dalam proses pembelajaran. Jika guru dan orang tua mengarahkan siswa/anak-anak mereka, maka siswa akan memberikan usaha yang tinggi untuk meraih prestasi dalam pembelajaran, khususnya biologi.

Self efficacy pada dasarnya adalah hasil dari proses kognitif berupa keputusan, keyakinan, atau pengharapan, motivasi tentang sejauhmana individu memperkirakan kemampuan dirinya dalam melaksanakan tugas atau tindakan tertentu yang diperlukan untuk mencapai hasil yang diinginkan (Bandura, 2011), self efficacy merupakan keyakinan dan 
kepercayaan seorang individu akan kemampuannya dalam mengontrol hasil dari usaha yang telah dilakukan (Novariandhini, 2012).

Dapat dijelaskan bahwa ketika self efficacy siswa rendah cenderung hasil belajar juga rendah. Sebaliknya, jika self efficacy siswa tinggi cenderung hasil belajar juga tinggi. Sejalan dengan pendapat Yoenanto, (2010), siswa yang memiliki self efficacy yang tinggi pada pembelajaran, ketika ia menjumpai soal-soal yang pelik ia akan dapat memecahkannya. Orang yang memiliki self efficacy yang rendah berkaitan dengan depresi, kecemasan, ketidakberdayaan, harga diri yang rendah, dan pesimis. Self efficacy memberi sumbangan dengan motivasi melalui beberapa cara yaitu dengan menentukan tujuan-tujuan bagi diri mereka sendiri (Siswati, 2015). Selanjutnya Bockler et al., (2017) mengatakan bahwa keadaan mental, seperti; pikiran, keyakinan, dan niat akan menjadi modal awal untuk memulai mencapai tujuan. Oleh karena itu, seseorang individu harus mampu mengontrol dirinya sendiri (thy self) untuk mencapai tujuan dalam hidupnya dan menjadi yakin juga tidak raguragu dalam mencapai tujuan tersebut. Maka hasil pembelajaran biologi dapat di pengaruhi keyakinan siswa terhadap dirinya sendiri.

Berdasarkan hasil perhitungan koefisien determinasi yang didapatkan, bahwa variabel X memberikan pengaruh terhadap variabel Y sebesar 0,00000161\%. Hasil ini membuktikan bahwa self efficacy siswa bukanlah satu-satunya faktor untuk meningkatkan hasil pembelajaran biologi, tetapi masih banyak lagi faktor yang mampu mempengaruhinya, salah satunya guru. Betapa tingginya nilai sebuah keberhasilan sehingga seorang guru berusaha sekuat tenaga dan pikiran mempersiapkan program pengajarannya dengan baik dan sistematik. Namun terkadang, keberhasilan yang dicita-citakan, tetapi kegagalan yang ditemui, disebabkan oleh berbagai faktor sebagai penghambatnya. Self efficacy adalah faktor yang penting dalam mempengaruhi prestasi siswa, memang self efficacy memiliki kesamaan dengan motivasi untuk menguasai motivasi intrinsik, namun lebih menitik beratkan pada kinerja atau hasil dibandingkan dengan prosesnya (Santrock, 2013). Sebaliknya, jika keberhasilan itu dapat tercapai, maka berbagai faktor itu juga menjadi pendukungnya.

Menurut Azwar, (2016) Ketika merasa cemas ataupun ketika dihadapkan dengan situasisituasi yang menekan, individu akan mengalami gejala-gejala fisik maupun psikologis. Apabila kondisi belajar tidak tenang maka pembelajaran akan menganggu keadaan psikologis siswa. Kondisi Psikologis yang dipenuhi dengan rasa takut dan cemas menghadapai ujian sehingga berdampak pada self efficacy siswa itu sendiri (Astuti dan Purwanto, 2014). Maka perlu rasanya self efficacy untuk diketahui, pengukuran secara tepat dan hasilnya dapat dimanfaatkan oleh guru atau lembaga sekolah untuk perbaikan atau bimbingan (Hairida, 2017).

\section{KESIMPULAN}

Terdapat korelasi yang positif namun tidak signifikan antara self efficacy siswa dengan hasil pembelajaran biologi kelas XI MIPA di SMAN 1 Rambatan dengan kreteria sedang. Namun demikian self efficacy siswa bukanlah satu-satunya faktor untuk meningkatkan hasil pembelajaran biologi siswa, tetapi masih banyak lagi faktor yang mampu mempengaruhinya.

\section{REFERENSI}

Alfurofika, P. S., Waluya, St.B., dan Suparna. 2013. Model pembelajaran Jigsaw dengan strategi belajar metakognitif untuk meningkatkan self-efficacy dan kemampuan pemecahan masalah. Unnes Journal Of Mathematics Education Research, 2(2): 128-133. 
Arikunto. 2010. Dasar-dasar evaluasi pendidikan. Bumi Aksara. Jakarta. 310 hlm.

Astuti, R.P., dan Purwanto, E. 2014. Perbedaan Self Efficacy siswa dalam menghadapi ujian nasional di SMP Negeri 1 Boyolali ditinjau dari keikutsertaan bimbingan belajar. Educational Psychology Journal, 3(1), 19-25.

Azwar, S. 2016. Efikasi diri dan prestasi belajar statistika pada mahasiswa. Jurnal Psikologi, 23(1), 33-40.

Bandura, A. 2010. Self efficacy. In Encyclopedia of human behavior Academic Press. pp. 71-81. http://www.uky.edu.html

Bandura, A. 2011. On the functional properties of perceived self-efficacy revisited. Journal of Management, 38(1): 9-44. https://doi.org/10.1177/0149206311410606

Bockler, A., Herrmann, L., Trautwein, F.M., Holmes, T., and Singer, T. 2017. Know Thy Selves: Learning to Understand Oneself Increases the Ability to Understand Others. Journal of Cognitive Enchancement, 1:197-209. https://doi.org/10.1007/s41465-0170023-6

Hairida. 2017. Pengembangan instrumen untuk mengukur self efficacy siswa dalam pembelajaran kimia. Edusains, 9(1): 53-59. doi:http://dx.doi.org/10.15408/es.v9i1.4000

Hanifah. 2012. Penigkatan Self Efficacy dan berpikir kritis melalui penerapan model pembelajaran Inkuiri materi pokok asam basa kelas XI SMAN 9 Surabaya. Unesa Journal of Chemical Education, 1(2): 27-33.

Herdani, T. P., Sartono, N., dan Evriyani, D. 2015. Pengembangan Permainan Monopoli Termodifikasi Sebagai Media Pembelajaran pada Materi Sistem Hormon (Penelitian dan Pengembangan di SMAN 1 Jakarta). Biosfer, 8(1): 20-28.

Lufri. 2010. Metodologi Penelitian: Strategi Pembelajaran Biologi Teori, Praktek, dan Penelitian. Padang. Negeri Padang University Press. Padang. 278 hlm.

Novariandhini, D. A. 2012. Harga Diri, Efikasi Diri, Motivasi Belaar, dan Berprestasi Akademik Siswa SMA Pada Berbagai Model Pembelajaran. Jurnal Ilmu Keluarga \& Konsumen, 5(2): 138-146.

Ormrod, J. E. 2010. Psikologi Pendidikan. R. Rahmat, \& A. Kumara (Eds.), Erlangga. Jakarta. 435 hlm.

Pajares, F. 2003. Self-Efficacy beliefs, motivation and achievement in writing: A Review of the literature. Reading \& Writing Quarterly, 19: 139-158. https://doi.org/10.1080/ 10573560308222

Rustaman, N., Dirdjosoemarto, S., Yudianto, S.A., Achmad, Y., Subekti, R., Rochintaniawati, D., Nurjhani, M. 2012. Strategi belajar mengajar biologi. Universitas Negeri Malang. Malang. $233 \mathrm{hlm}$.

Santrock, J.W. 2007. Psikologi Pendidikan. Kencana Prenada Media Group. Jakarta. 519 hlm.

Schunk, D.H., and Meece, J.L. 2006. Self-efficacy development in adolescenceso. In F. Pajares, \& T. Urdan (Eds.). Self-efficacy Beliefs of Adolescents. Greenwich, CT: Information Age Publishing. pp. 71-96. 
Siswati, S. 2015. Hubungan kompetensi pedagogic guru dan efikasi diri dengan motivasi berprestasi belajar siswa kelas IX SMP Islam Al-Ulum Terpadu Medan. (Thasis). Program Studi Magister Psikologi. Universitas Medan Area. Medan.

Subana dan Sudrajat, M.R. 2015. Statistik Pendidikan. Pustaka Setia. Bandung. 224 hlm.

Sudjana, N. 2011. Metoda Statistika. Tarsito. Bandung. 239 hlm

Suryabrata, S. 2011. Psikologi Pendidikan. PT Raja Grafindo Persada. Jakarta. 370 hlm.

Yoenanto, N.H. 2010. Hubungan antara Self-regulated learning dengan Self Efficacy pada siswa akselerasi Sekolah Menengah Pertama di Jawa Timur. Journal of Educational Psychology, 2(12): 88-94.

\section{Authors:}

Diyyan Marneli, Department of Biology Education, Faculty of Education and Teacher Training, Institut Agama Islam Negeri Batusangkar, Jl. Jenderal Sudirman No.137, Lima Kaum, Tanah Datar, West Sumatera 27217. Indonesia, email: diyyanmarneli@iainbatusangkar.ac.id

Hanif Dirma, Department of Biology Education, Faculty of Education and Teacher Training, Institut Agama Islam Negeri Batusangkar, Jl. Jenderal Sudirman No.137, Lima Kaum, Tanah Datar, West Sumatera 27217. Indonesia, email: hanifdirma@gmail.com

Rina Delfita, Department of Biology Education, Faculty of Education and Teacher Training, Institut Agama Islam Negeri Batusangkar, Jl. Jenderal Sudirman No.137, Lima Kaum, Tanah Datar, West Sumatera 27217. Indonesia, email: rinadelfita@iainbatusangkar.ac.id

This is an open-access article distributed under the terms of the Creative Commons Attribution License, which permits unrestricted use, distribution and reproduction in any medium, provided the original author and source are credited. (http://creativecommons.org/licenses/by/4.0/).

\section{How to cite this article:}

Marneli, D., Dirma, H., and Delfita, R. 2020. Self efficacy correlation with biological learning results in High School 1 Rambatan, Districts Tanah Datar, West Sumatra. Simbiosa, 9(2): 157-164. Doi. http://dx.doi.org/10.33373/sim-bio.v9i2.2677 